\title{
Association between Dietary Habits and Asthma Severity in Children
}

\author{
Denise Halpern Silveira, *Linjie Zhang, *Silvio O M Prietsch, ${ }^{*}$ Amilcare Angelo Vecchi AND *Lulie \\ ROSANE ODEH SUSIN \\ From the School of Nutrition, Federal University of Pelotas; *Postgraduate Program in Health Sciences, Faculty of Medicine, \\ Federal University of Rio Grande, Rio Grande; and ${ }^{\#}$ Faculty of Medicine, Federal University of Pelotas, Pelotas; Brazil. \\ Correspondence to: Dr Denise Halpern Silveira, Rua Raimundo Correia, 155, 96055-700- Três Vendas, Pelotas, RS-Brazil. \\ denise_hs@hotmail.com.br \\ Received: June 21, 2014; Initial review: September 22, 2014; Accepted: November 07, 2014.
}

Objective: To investigate association between dietary habits and asthma severity in children.

Design: Cross-sectional study.

Setting: Two teaching hospitals in Brazil.

Participants: Cases $(n=268)$ were children (3-12yr) with persistent asthma and age-matched controls $(n=126)$ were those with intermittent asthma.

Main outcome measures: Dietary habits were determined based on food consumption in the past 12 months classified as frequent ( $\geq 3$ times per week) or infrequent (never or $<3$ times per week).Nutritional status was classified into two categories according to WHO Child Growth Standards: obese: >2Z-score of BMI-for-age; non-obese: $\leq 2 Z$-score of BMI-for-age.
Results: After adjusting for confounding factors, maternal smoking during pregnancy, preterm birth and obesity were significantly associated with persistent asthma, with adjusted ORs (95\% Cl) of 2.11 (1.08- 4.13), 2.61(1.07-6.35) and 2.89 (1.49-5.61), respectively. No significant association was observed between frequency of consumption of specific foods, food groups, or dietary pattern (pro- or contra-Mediterranean diet) and the severity of asthma.

Conclusions: This study did not find a significant association between dietary habits and asthma severity in children. Maternal smoking during pregnancy, preterm birth and obesity were independent factors associated with persistent asthma.

Keywords: Asthama, Brazil, Diet, Epidemiology, Risk factors.
A sthma is the most common chronic disease in childhood. In spite of advances in the knowledge of pathophysiology and treatment of the disease, the prevalence and severity of asthma in children has increased over the last few decades [1,2]. It has been proposed that changes in dietary habits may be one of the factors responsible for this increase [3-5]. Numerous epidemiological studies have been conducted to investigate the association between dietary habits and the risk of asthma in children. These studies have identified the intake of fruits, vegetables and fish as protective factors against childhood asthma while fast food consumption as a risk factor for the disease [6-11]. Studies on dietary habits and severity of asthma are few and show reconsistent results [11-13]. The present study aimed to investigate the association between dietary habits and the severity of childhood asthma.

\section{Methods}

This cross-sectional study was conducted at the Pediatric Pulmonary Outpatient clinics of two University teaching hospitals of Brazil between April 2012 and May 2013.
These clinics are the only two public specialized services for asthmatic children covering a region with around 500,000 inhabitants. The research project and written informed consent forms were approved by the Research Ethics Committee of the two Universities. Informed written consent was obtained from all patients or guardians.

Accompanying Editorial: Pages 19-22.

Children aged 3 to12 years with diagnosis of asthma were eligible for the study. The clinical criteria for diagnosis of asthma were based on the recommendations of the British Thoracic Society Guidelines, 2009 [14]. The diagnosis of asthma was made if all the following criteria were met: $(i)$ recurrent episodes $(\geq 3)$ of one or more of the following symptoms - wheeze, cough, breathing difficulties and chest tightness, particularly at night or in the early hours of the morning; (ii) respiratory symptoms improve spontaneously or after treatment (bronchodilators with or without corticosteroids); (iii) presence of triggers or aggravating factors such as exposure to allergens or irritants, physical exercise, 
weather changes or emotional stress; and (iv) personal history of atopy (allergic rhinitis or eczema) and/or family history of atopy (asthma, allergic rhinitis or eczema) in first-degree relatives. The severity of asthma was assessed based on the clinical criteria recommended by the National Heart, Lung, and Blood Institute (NHLBI), and was classified as intermittent asthma or persistent asthma (mild, moderate or severe) [15]. The diagnosis and classification of asthma were performed by three senior pulmonologists who provided specialized care for asthmatic children at the two clinics.

The cases were children with persistent asthma (mild, moderate or severe) while the controls were those with intermittent asthma. Due to the limited number of children with intermittent asthma attending the clinics, we recruited one control for two cases matched by age groups: 36 to 72 months and 73 to 144 months. We excluded children with broncho-pulmonary dysplasia, cystic fibrosis, congenital cardiopulmonary diseases, immunodeficiency, chronic encephalopathy, and those who had changed their dietary habits under the advice of physician or nutritionist in the past year.

Data collection was carried out through interview with the parents or guardians of the patient using a standard pre-coded questionnaire. All investigators were blinded to the classification of asthma severity. The dependent variable was asthma severity, classified as persistent or intermittent, while independent variables were: dietary habits, demographic and socioeconomic data (gender, age and skin color, family income and educational level of parents), smoking during pregnancy, presence of allergens in the home (curtains, carpets, fluffy toys or pets), gestational age (preterm $<37$ weeks), birth weight (low birthweight $<2500 \mathrm{~g}$ ), family history of asthma (first-degree relatives) and personal history of allergic rhinitis. Dietary habits were determined based on the consumption of specific foods or food groups in the past 12 months. The frequency of food intake was classified into two categories adapted from criteria used in the literature: frequent when intake was three or more times per week, and infrequent when never consumed or intake twice per week or less $[12,13]$. Specific food or food groups included: milk or yoghurt, meats (bovine, pork, and poultry), vegetables (leafy and non-leafy), fish, eggs, fruit, legumes (beans, peas, lentils, and chick peas), roots and tubers (potato, sweet potato, manioc), grains (rice, pasta, bread), butter, soft drinks and processed foods including fast food. Mediterranean diet pattern (MD) was created based on criteria adapted from the literature: pro-MD pattern (fruit, vegetables, fish, fruit juices, root vegetables and tubers and grains) and a contra-MD diet (milk, meat, eggs, processed foods, soft drinks, butter). The Mediterranean diet was classified as "yes" when intake of at least 5 foods in each group was frequent ( $\geq 3$ times per week) [12]. Nutritional status was measured using the Body Mass Index (BMI) calculated by dividing body mass $(\mathrm{Kg})$ by height ${ }^{2}\left(\mathrm{~m}^{2}\right)$. The weight was measured by a mechanical platform scale with capacity up to $150 \mathrm{Kg}$ (Filizola) and height was measured by a stadiometer (AlturaExata). Measurements were made using standardized methodology [16]. Nutritional status was classified into two categories according to WHO Reference Growth Standards: Obese, children with a Z-score of BMI-forage $>2$ and non-obese, children with a Z-score of BMIfor-age $\leq 2$ [17].

Statistical analysis: Double data entry was performed using the software EPI-data 3.2. Analyses were carried out using the statistics package Stata 11 (Stata Corp., College Station, USA). A descriptive analysis was conducted for each group with calculation of absolute and relative frequencies for independent variables. Crude and adjusted odds ratios (OR) and 95\% confidence intervals (95\% CI) were calculated using conditional logistic regression given the matching of cases and controls by age groups [18]. Multivariate analysis was applied to control for potential confounding factors, with inclusion of variables according to the preestablished hierarchical levels as follows: level 1: gender, skin color, maternal schooling, income, paternal schooling, and smoking during pregnancy; level 2: allergens in the home, gestational age, birth weight, family history of allergic rhinitis, exposure to passive smoking; level 3: dietary variables; and level 4: obesity. Only the variables with $P \leq 0.20$ remained in the model. $P<0.05$ was considered statistically significant.

\section{Results}

A total of 404 patients were screened for eligibility, of which 10 were excluded due to diagnosis of bronchopulmonary dysplasia $(n=3)$, chronic neurological disease $(n=2)$, pulmonary tuberculosis $(n=1)$, congenital heart diseases $(n=3)$ and not having a diagnosis of asthma $(n=1)$. Thus, 394 patients were included in the study, of whom 268 were classified as the cases (persistent asthma) and 126 as the controls (intermittent asthma). Table I shows the characteristics of 394 patients. Bivariate analysis showed that male gender, maternal smoking during pregnancy and obesity were significantly associated with persistent asthma. The frequency of intake of specific food or food groups was not significantly associated with asthma severity (Table II). After adjusting for confounding factors, maternal smoking during pregnancy, preterm birth and 
TABLE I CHARACTERISTICS OF THE STUDY POPULATION $(N=394)$

\begin{tabular}{|c|c|c|c|c|}
\hline Variables & $\begin{array}{l}\text { Persistent asthma } \\
(n=268) n(\%)\end{array}$ & $\begin{array}{l}\text { Intermittent asthma } \\
\quad(n=126) n(\%)\end{array}$ & OR $(95 \%$ CI $)$ & Pvalue \\
\hline Male gender & $159(59.3)$ & $61(48.4)$ & $1.58(1.03-2.42)$ & 0.03 \\
\hline Non-white race & $80(30.0)$ & 39 (30.9) & $0.96(0.60-1.52)$ & 0.85 \\
\hline Family income: $2^{\circ}$ tertile & $76(30.2)$ & $38(31.4)$ & $0.89(0.52-1.52)$ & \\
\hline $3^{\circ}$ tertile & $82(32.5)$ & $42(34.7)$ & $0.88(0.52-1.48)$ & $0.86^{*}$ \\
\hline \#Maternal smoking & $66(24.8)$ & $18(14.4)$ & $1.90(1.07-3.37)$ & 0.02 \\
\hline Presence of allergens in home & $254(95.1)$ & $121(96.0)$ & $0.81(0.28-2.31)$ & 0.68 \\
\hline Gestational age $<37$ wks & $47(18.5)$ & $15(13.3)$ & $1.49(0.79-2.79)$ & 0.21 \\
\hline Birth weight $<2.5 \mathrm{Kg}$ & $37(14.5)$ & $18(15.4)$ & $0.93(0.51-1.72)$ & 0.83 \\
\hline Maternal education $<9$ y & $127(47.7)$ & $69(55.2)$ & $0.76(0.49-1.17)$ & 0.21 \\
\hline Paternal education $<9 y$ & $163(64.9)$ & $78(69.0)$ & $0.82(0.51-1.32)$ & 0.41 \\
\hline Family history of asthma & $159(59.5)$ & $70(56.0)$ & $1.13(0.74-1.75)$ & 0.55 \\
\hline Family history of allergic rhinitis & $193(72.8)$ & $84(67.2)$ & $1.37(0.86-2.18)$ & 0.19 \\
\hline Passive smoking & $123(46.1)$ & $46(36.5)$ & 1.47 (0.95-2.27) & 0.08 \\
\hline \$Obesity & $83(32.9)$ & $22(18.2)$ & $2.20(1.30-3.74)$ & $<0.001$ \\
\hline
\end{tabular}

P value estimated by Wald test for heterogeneity; ${ }^{*}$ Wald test for linear trend; ${ }^{*}$ during pregnancy; ${ }^{\$}$ Z-score of BMI- for-age $>2$.

obesity were significantly associated with persistent asthma, with OR (95\% CI) of 2.11 (1.08-4.13), 2.61(1.07-6.35) and 2.89 (1.49-5.61), respectively (Table III). No significant association was observed between dietary habits and asthma severity.

\section{Discussion}

This cross-sectional study did not show significant association between frequency of consumption of specific foods, food groups, or dietary pattern (pro- or contra-Mediterranean diet) and the severity of asthma in children aged 3 to 12 years.

Several limitations should be taken into account when interpreting the results of this study. The statistical power of the study may be insufficient for investigating the association between diet and asthma severity due to a relatively small sample size. The broad age range of the participants (3 to 12 year) may act as a confounding factor given that food consumption may vary substantially among children of different age groups. In order to control for the confounding effect of age, the cases and controls were matched by age-groups. We did not recruit non-asthmatic children as controls because this study aimed to investigate association between dietary habits and asthma severity rather than risk of asthma. This study was hospital-based, and therefore the results may not necessarily be extrapolated to general population of asthmatic children. Mild persistent, moderate persistent and severe persistent asthma were combined into a single "persistent asthma" category given that inter-observer agreement increases with reduced number of categories [26]. Moreover, this simplified classification for asthma severity (intermittent vs. persistent) had a practical implication because only children with persistent asthma need long-term controller medications.

To date, there is limited and inconsistent evidence about association between diet and asthma severity in children. Recently, Ellwood, et al. [4,13] reported the global results of the ISAAC study (Phase III) on the association between food consumption in the last 12 months and atopic diseases such as asthma, rhinoconjuctivitis and eczema. Fruit intake $\geq 3$ times per week was found to be a protective factor against severe asthma in both adolescents and children, with OR (95\% CI) of $0.89 \quad(0.82-0.97$ and $0.86 \quad(0.76-0.97)$, respectively. Fast food consumption $\geq 3$ times per week was a risk factor for severe asthma in two populations, with OR (95\% CI) of 1.39 (1.30-1.49) and 1.27 (1.131.42), respectively. However, some inconsistent findings were observed between two populations, and there was also heterogeneity of findings across different study centers and countries [13]. In the present study, fruit consumption $\geq 3$ times a week appeared to be a protective factor against persistent asthma, with an OR of 0.85 (95\% CI 0.48-1.50), although the result was not 
TABLE II Bivariate Analysis of Association Between Dietary Habits and Asthma Severity (N=394)

\begin{tabular}{lcccc}
\hline $\begin{array}{l}\text { Food consumption* } \\
\geq 3 \text { times/wk }\end{array}$ & $\begin{array}{c}\text { Persistent asthma, No.(\%) } \\
(n=268)\end{array}$ & $\begin{array}{c}\text { Intermittent asthma, No.\% } \\
(n=126)\end{array}$ & OR(95\% CI) \\
\hline Milk & $249(94.3)$ & $118(94.4)$ & $0.95(0.37-2.40)$ & 0.91 \\
Vegetables & $183(69.3)$ & $81(65.3)$ & $1.18(0.75-1.86)$ & 0.47 \\
Meat & $228(85.7)$ & $114(90.5)$ & $0.63(0.32-1.25)$ & 0.19 \\
Fish & $52(19.7)$ & $22(17.3)$ & $1.14(0.66-2.00)$ & 0.65 \\
Eggs & $114(42.9)$ & $54(42.9)$ & $0.98(0.64-1.51)$ & 0.93 \\
Processed food & $188(70.7)$ & $85(68.5)$ & $1.10(0.70-1.75)$ & 0.67 \\
Soft drink & $104(38.9)$ & $53(42.4)$ & $0.88(0.57-1.36)$ & 0.57 \\
Pulses & $235(88.4)$ & $115(90.5)$ & $0.80(0.40-1.61)$ & 0.53 \\
Roots & $136(50.9)$ & $57(45.6)$ & $1.22(0.80-1.87)$ & 0.36 \\
Cereals & $261(98.1)$ & $124(97.6)$ & $1.25(0.29-5.29)$ & 0.77 \\
Butter & $213(80.4)$ & $110(86.5)$ & $0.64(0.35-1.16)$ & 0.15 \\
Fruits & $211(80.5)$ & $102(82.3)$ & $0.85(0.48-1.50)$ & 0.58 \\
Pro-Mediterranean diet & $146(57.0)$ & $63(52.0)$ & $1.20(0.78-1.86)$ & 0.40 \\
Contra-Mediterranean diet & $101(38.8)$ & $53(43.5)$ & $0.82(0.53-1.27)$ & 0.38 \\
\hline
\end{tabular}

TABLE III Adjusted Analysis of Association Between PATIENT CHARACTERISTICS VARIABLES AND ASTHMA SEVERITY

\begin{tabular}{llr}
\hline Variables & OR $(95 \%$ CI $)$ & Pvalue \\
\hline${ }^{*}$ Male gender & $1.58(0.97-2.55)$ & 0.06 \\
*Family income & $0.86(0.48-1.57)$ & 0.19 \\
${ }^{*}$ Paternal education level <9y & $0.68(0.40-1.17)$ & 0.17 \\
${ }^{*}$ Smoking in pregnancy & $2.11(1.08-4.13)$ & 0.03 \\
\#Gestational age <37 wks & $2.61(1.07-6.35)$ & 0.04 \\
\$Butter $\geq 3$ times/wk & $0.60(0.30-1.21)$ & 0.15 \\
‡Obesity & $2.89(1.49-5.61)$ & $<0.01$ \\
\hline
\end{tabular}

*level 1; " level 2; ${ }^{\$}$ level 3; ${ }^{*}$ level 4.

statistically significant. The conflicting findings regarding the association between Mediterranean diet and asthma severity in children were also found in two studies with similar research methodology and population [11,12]. The inconsistency of the results on diet and asthma severity across different studies, even though among different populations within the same study, may be attributable to sampling error and/or other associated factors such as memory bias, accuracy of the diagnosis and classification of asthma, variation in food types among different geographical regions as well as biological variation among study populations. These factors should be taken into account in the future researches on diet and asthma severity in children.
The present study showed that maternal smoking during pregnancy was associated with more severe asthma in children. Smoking represents a modifiable risk factor for respiratory infections and asthma in childhood. In utero exposure to maternal smoking has a direct effect on the development of respiratory system of the fetus, with compromised development and function of the lungs in infants $[19,20]$.

This study identified preterm birth as an independent factor associated with persistent asthma. The relationship between gestational age and asthma severity has been investigated in previous studies with conflicting results $[21,22]$. The present study showed that obesity was significantly associated with more severe childhood asthma. This finding is consistent with that reported in previous studies [23-25].

In conclusion, this study shows that obesity rather than dietary habits is significantly associated with asthma severity in children. Other independent factors associated with persistent asthma included maternal smoking during pregnancy and preterm birth.

Acknowledgements: Grégore Mielke, epidemiologist, for conducting statistical analysis, and Samuel de Carvalho Dumith, epidemiologist, for help in classifying nutritional status of the participants. Nathalia Cardoso Salomão and Matheus Wicth participated in collection and management of the data.

Contributors: DHS: data collection, management and interpretation, and manuscript writing; LZ: conceived the study, participated in collection and interpretation of the data, 


\section{What is AlReady Known?}

- There is inconsistent evidence of association between dietary habits and the severity of childhood asthma.

\section{What This Study Adds?}

- Obesity, rather than dietary habits, is significantly associated with asthma severity in children.

and approved the final version of the article; SOP: participated in data collection and approved the final version of the article; AAV: participated in data collection and approved the final version of the article; and LROS: participated in interpretation of the data and approved the final version of the article. Funding: None; Competing interests: None stated.

\section{REFERENCES}

1. Global Strategy for Asthma Management and Prevention, Global Initiative for Asthma (GINA) (2012). Available from: http// www.ginasthma.org. Accessed February16, 2013.

2. Asher MI. Recent perspectives on global epidemiology of asthma in childhood. Allergol Immunopathol. 2010; 8:83-7.

3. Patel S, Murray CS, Woodcock A, Simpson A, Custovic A. Dietary antioxidant intake, allergic sensitization and allergic diseases in young children. Allergy. 2009;64:1766-72.

4. Ellwood P, Asher MI, Bjorksten B, Burr M, Pearcez N, Robertson CF. Diet and asthma, allergic rhinoconjunctivitis and atopic eczema symptom prevalence: an ecological analysis of the International Study of Asthma and Allergies in Childhood (ISAAC) data. ISAAC Phase One Study Group. Eur Respir J. 2001;17:436-43.

5. Huang SL, Lin KC, Pan WH. Dietary factors associated with physician-diagnosed asthma and allergic rhinitis in teenagers: analyses of the first Nutrition and Health Survey in Taiwan. Clin Exp Allergy. 2001;31:259-64.

6. Chatzi L, Torrent M, Romieu I, Garcia-Esteban R, Ferrer $\mathrm{C}$, Vioque J, et al. Diet, wheeze, and atopy in school children in Menorca. Spain Pediatr Allergy Immunol. 2007;18:480-5.

7. Nagel G, Weinmayr G, Kleiner A, Garcia-Marcos L, Strachan DP. ISAAC Phase Two Study Group. Effect of diet on asthma and allergic sensitisation in the International Study on Allergies and Asthma in Childhood (ISAAC) Phase Two. Thorax. 2010;65:516-22.

8. Wickens K, Barry D, Friezema A, Rhodius R, Bone N, Purdie G, et al. Fast foods - are they a risk factor for asthma? Allergy. 2005;60:1537-41.

9. Gutiérrez-Delgado RI, Barraza-Villarreal A, EscamillaNúñez MC, Solano-González M, Moreno-Macías $H$, Romieu I. Consumo de alimentos y asma enniños escolares de Cuernavaca. Salud Publica Mex. 2009;51:202-11 [Spanish].

10. Tabak C, Wijga AH, de Meer G, Janssen NAH, Brunekreef B, Smiti HA. Diet and asthma in Dutch school children (ISAAC-2). Thorax. 2006;61:1048-53.
11. Garcia-Marcos L, Canflanca IM, Garrido JB, Varela AL, Garcia-Hernandez G, GuillenGrima F, et al. Relationship of asthma and rhinoconjunctivitis with obesity, exercise and Mediterranean diet in Spanish schoolchildren. Thorax. 2007;62:503-8.

12. Gonzalez Barcala FJ, Pertega S, Bamonde L, Garnelo L, Perez Castro T, Sampedro M, et al. Mediterranean diet and asthma in Spanish schoolchildren. Pediatr Allergy Immunol. 2010;21:1021-7.

13. Ellwood P, Asher MI, García-Marcos L, Williams H, Keil $\mathrm{U}$, Robertson C, et al. Do fast foods cause asthma, rhinoconjunctivitis and eczema? Global findings from the International Study of Asthma and Allergies in Childhood (ISAAC) Phase Three. Thorax. 2013;68:351-60.

14. British Thoracic Society. British Guideline on the Management of Asthma (2009) Available from: http:// www.brit-thoracic.org.uk. Guidelines/ AsthmaGuidelines.aspx. Accessed October 21, 2011.

15. National Heart, Lung, and Blood Institute. Expert Panel Report 3: Guidelines for the Diagnosis and Management of Asthma (2007) Available from: http:// www.nhlbi.nih.gov/guidelines/asthma/asthgdln.htm. Accessed October 21, 2011.

17. WHO Multicentre Growth Reference Study Group. WHO Child Growth Standards: Length/height-for-age, weightfor-age, weight-for-length, weight-for-height and body mass index-for-age: Methods and development. Geneva: World Health Organization (2006) Avaiable from: http:// www.who.int/childgrowth/publications/technical_ report_pub/en/. Accessed February 16, 2013.

18. Breslow NE, Day NE. Statistical methods in cancer research: The analysis of case-control studies. Scientific publications 32. Lyon: International Agency for Research on Cancer (IARC) 1980.

19. Gilliland FD, Berhane K, Li YF, Rappaport EB, Peters J. Effects of early onset asthma and in utero exposure to maternal smoking on childhood lung function. Am J Respir Crit Care Med. 2003;167:917-24.

20. Gilliland FD, Li YF, Peters JM. Effects of maternal smoking during pregnancy and environmental tobacco smoke on asthma and wheezing in children. Am J Respir Crit Care Med. 2001;163:429-36.

21. Goyal NK, Fiks AG, Lorch S. Association of late-preterm birth with asthma in young children: practice-based study. Pediatrics. 2011;128:830-8.

22. Abe K, Shapiro-Mendoza CK, Hall LR, Satten GA. Late preterm birth and risk of developing asthma. J Pediatr. 2010;157:74-8.

23. Mai XM, Nilsson L, Axelson O, Braback L, Sandin A, Kjellman NI, et al. High body mass index, asthma and 
allergy in Swedish schoolchildren participating in the International Study of Asthma and Allergies in Childhood: Phase II. Acta Paediatr. 2003;92:1144-8.

24. Quinto KB, Zuraw BL, Poon KY, Chen W, Schatz M, Christiansen SC. The association of obesity and asthma severity and control in children. J Allergy Clinl Immunol. 2011;128:964-9.
25. Michelson PH, Williams LW, Benjamin DK, Barnato AE. Obesity, inflammation, and asthma severity in childhood: data from the National Health and Nutrition Examination Survey 2001-2004. Ann Allergy Asthma Immunol. 2009;103:5:381-5.

26. Baker KM, Brand DA, Hen J, Jr. Classifying asthma: Disagreement among specialists. Chest. 2003;124:2156-63. 